\section{$\underset{\substack{\text { hommes } \\ \text { \& migrations }}}{ }$}

\section{Hommes \& migrations}

Revue française de référence sur les dynamiques

migratoires

$1324 \mid 2019$

Religion et discrimination

\title{
Une solitude peuplée
}

\section{Mohamed Mbougar Sarr}

\section{QpenEdition \\ Journals}

\section{Édition électronique}

URL : https://journals.openedition.org/hommesmigrations/8963

DOI : 10.4000/hommesmigrations.8963

ISSN : 2262-3353

\section{Éditeur}

Musée national de l'histoire de l'immigration

\section{Édition imprimée}

Date de publication : 1 janvier 2019

Pagination : 184-186

ISBN : 978-2-919040-44-5

ISSN : $1142-852 X$

\section{Référence électronique}

Mohamed Mbougar Sarr, «Une solitude peuplée », Hommes \& migrations [En ligne], 1324 | 2019, mis en ligne le 01 janvier 2019, consulté le 06 janvier 2022. URL : http://journals.openedition.org/

hommesmigrations/8963; DOI : https://doi.org/10.4000/hommesmigrations.8963 


\section{LHTHERATURE}

\section{Une solitude peuplée}

Mohamed Mbougar Sarr,

écrivain, lauréat du Prix littéraire de la Porte Dorée 2018.

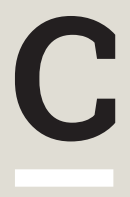

e que peut la littérature, pourrais-je, de manière un peu tautologique, hasarder, c'est dire ce qu'aucune autre parole que la sienne n'est en mesure de dire sur une expérience humaine. Je crois qu'il y a, pour toute expérience de notre condition, une part de vérité que la littérature seule peut chercher, dévoiler, révéler. Là est son privilège ; là est aussi sa modestie. C'est une telle idée qui a guidé l'écriture de Silence du chœur lorsque, fin 2015, dans un petit village sicilien où un ami poète m'avait conduit et où je rencontrai plusieurs réfugiés qu'on y accueillait plus ou moins facilement, j'ai eu l'intuition que c'était par la fiction littéraire que je parviendrais le mieux à transfigurer ce réel-là, celui du drame des migrants, pour en révéler la complexité, en montrer la densité anthropologique, en dire à la fois la singularité et l'universalité. C'est aussi cette idée qui m'accompagnera lors de cette résidence au Musée national de l'histoire de l'immigration. Celle-ci sera pour moi, au-delà des différents enjeux et projets qui en constitueront le programme, une manière autre, collaborative, pratique, ouverte, hétérotopique, de poursuivre le défrichage et le déchiffrage de quelques questions nées dans l'écriture: Que peut-on savoir d'une personne qui part? Arriver est-il plus difficile que partir ? Qu'est-ce qu'accueillir et qu'est-ce qu'être accueilli ? Que peut-on dire sur l'indicible de l'exil ? Y a-t-il une langue universelle de l'exil ? Ce ne sont là que quelques questions que j'aimerais creuser lors de cette résidence. D'autres naîtront des échanges que j'y aurai ; certaines se transformeront, se préciseront, s'étofferont. L'essentiel, pour moi, sera d'accompagner une réflexion littéraire régulière et participative dans les activités du Musée. À cet effet, mon travail en ce lieu reposera sur cinq activités principales.

L e premier projet consistera à animer un atelier d'écriture avec des réfugiés autour de la vie entre les langues. Il y sera question d'accompagner ces réfugiés dans l'écriture d'un texte individuel sur leur passage de leur langue d'origine au français, en insistant notamment sur les différents modes (intime, administratif) de la traduction comme élément essentiel de la possibilité d'une rencontre humaine. Il s'agira ainsi d'aborder la question du « récit » ou de la 《 relation » (la polysémie de ce dernier terme sera intéressante à creuser) par le biais de la langue. Quels mots pour dire dans une langue nouvelle ce qui relève de l'intimité la plus profonde, de la langue la plus ancienne, donc ? La traduction peut-elle traduire ce qui semble a priori intraduisible, enfoui, 
irréductible à l'usage d'une nouvelle langue ? L'intérêt, à mes yeux, réside ici dans le fait de partir de problèmes, de sentiments qu'on penserait incommunicables car trop liés à une mélancolie secrète, pour ensuite essayer, patiemment, par la traduction, de voir ce qu'il advient de cette matière biographique. La publication d'un livre et/ou d'un CD viendrait valider cet atelier, dont on pourrait prévoir une séance finale de restitution au musée ; séance pendant laquelle les réfugiés pourraient lire ou jouer leur texte.

Il s'agira, pour la deuxième activité, d'un cycle d'interventions dans les lycées partenaires du Musée (ou directement au Musée). Ces rencontres seraient l'occasion d'échanger avec les jeunes sur les questions actuelles de migrations ou sur le rôle possible de la littérature dans la compréhension de ces phénomènes. Elles pourraient ainsi permettre aux lycéens de jeter, grâce à la littérature, un regard autre sur les situations géopolitiques. D'une certaine manière, ces discussions apporteront, par l'acte, des pistes de réponses à des questions que beaucoup de jeunes (et pas seulement eux) se posent souvent : qu'est-ce qu'être un écrivain vivant? En quoi consiste la vie quotidienne d'un auteur ? À quoi sert la littérature face aux maux et crises du monde? Certaines classes de ces lycées pourraient en outre être concernées par la lecture des livres sélectionnés pour le Prix littéraire de la Porte Dorée. Le cas échéant, il serait possible de réfléchir avec eux aux romans proposés.

Le troisième axe de travail sera ma participation et ma contribution, comme écrivain et chercheur, aux activités du Musée national de l'histoire de l'immigration et de ses partenaires. Le Musée national de l'histoire de l'immigration

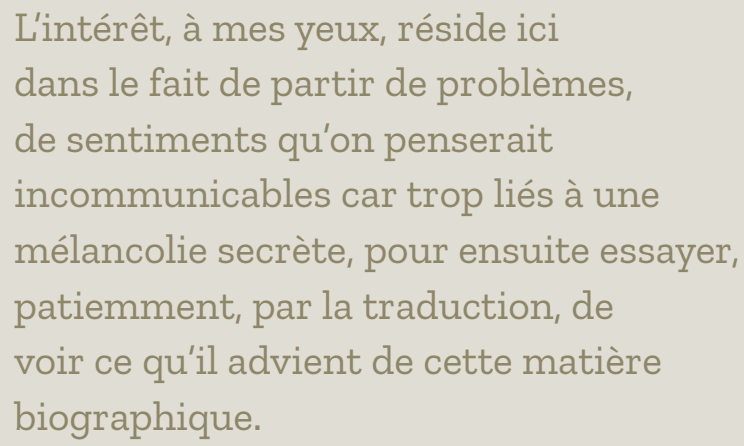

L'intérêt, à mes yeux, réside ici dans le fait de partir de problèmes, de sentiments qu'on penserait incommunicables car trop liés à une mélancolie secrète, pour ensuite essayer, patiemment, par la traduction, de voir ce qu'il advient de cette matière biographique. organise ou collabore à des événements auxquels j'aimerais participer, comme auditeur ou intervenant. Je songe particulièrement au salon Littexil, mais aussi à des formations, ateliers, séminaires pour lesquels le Musée serait sollicité. J'aimerais également participer, comme juré, au Prix littéraire de la Porte Dorée, dont l'édition 2019 sera le dixième anniversaire. Enfin, je souhaiterais intervenir dans la revue Hommes \& Migrations sur des sujets ayant trait à la littérature et aux migrations.

La quatrième activité est la création d'un rendez-vous littéraire au sein du Musée, en partenariat avec la médiathèque, où se tiendraient des lectures de textes que je crois essentiels (romans, poésies, essais) sur la question de l'exil (lectures suivies de commentaires, discussions, débats), mais aussi des rencontres avec des écrivains dont l'œuvre traite de la question de l'exil. En tant qu'écrivain africain, il me serait possible d'inviter d'autres auteurs issus d'un « ailleurs » et ayant, dans leur travail, une réflexion intéressante sur la notion « d'ailleurs ». Cette activité, ouverte à tous les publics, s'inscrirait dans le sillage des cafés littéraires de la médiathèque, où les auteurs finalistes du Prix littéraire de la Porte Dorée sont reçus pour des discussions et des débats littéraires. 
La cinquième activité aurait trait à mon propre travail d'écriture. J'ai, en effet, formé le projet d'écrire un roman sur l'exil littéraire en m'inspirant de la vie et de l'œuvre du Malien Yambo Ouologuem (1940-2017), écrivain qui a connu les honneurs littéraires à Paris avec son premier roman (Le Devoir de violence, 1968) avant de disparaître de la scène publique après un scandale lié à des accusations de plagiat dans son livre. Il ne publiera presque plus rien pendant les cinquante ans qui ont suivi, et est décédé en 2017 dans un mystérieux et fascinant silence public. L'histoire de cet écrivain africain qui a quitté son pays pour chercher la lumière littéraire avant d'y retourner pour la fuir m'intéresse. C'est une histoire romanesque, qui donne matière à réflexion sur l'absolu littéraire mais aussi le « droit de s'en aller » tel que Baudelaire le réclamait de manière sibylline. Je pense que les différentes activités que je mènerai au musée féconderont très heureusement la préparation de ce roman qui me tient à cœur. Voilà pour mes projets.

Écrire, on le sait, est une affaire essentiellement solitaire. Mais c'est une solitude paradoxale, pleine du silence, mais aussi du bruit du monde, des récits d'hommes et de femmes dont les destins sont des miroirs de notre expérience de la condition humaine, et d'autres visages, et d'autres langues, et de rêves. Une œuvre naît souvent de la rencontre de nombreuses humanités venues d'ailleurs et allant ailleurs. Au Musée national de l'histoire de l'immigration, je serai le spectateur privilégié de ce merveilleux défilé. Il me tarde de vivre en cette belle solitude peuplée qu'une résidence littéraire crée toujours. 